\title{
Pair bonds during the annual cycle of a long-distance migrant, the Arctic Tern (Sterna paradisaea)
}

\author{
Chris P. F. Redfern * (1)
}

\begin{abstract}
Background: The extent to which pairs remain together during the annual cycle is a key question in the behavioural ecology of migratory birds. While a few species migrate and winter as family units, for most the extent to which breeding partners associate in the non-breeding season is unknown. The Arctic Tern (Sterna paradisaea) has one of the longest migrations of any species, and the aim of this study was to establish whether or not partners remain together after breeding.
\end{abstract}

Methods: Leg-mounted geolocators were fitted to breeding pairs of Arctic Terns nesting on the Farne Islands, Northumberland, UK. The devices were recovered for analysis the following year.

Results: Analysis of data for the six pairs which returned the following year showed that partners departed from the colony at different times after breeding and migrated independently to different Antarctic regions. Partners also departed from the Antarctic and turned to the breeding colony independently. One third of the pairs divorced on return.

Conclusions: For long-distance migrants reliant on unpredictable foraging opportunities, it may not be viable to remain as pairs away from the breeding colony. Synchrony in arrival times at the breeding colony may maximise the chance of retaining a familiar partner, but could be affected by environmental factors in wintering areas or along migration routes.

Keywords: Arctic Tern, Migration, Pair-bond, Partner association

\section{Background}

For migratory species, the extent to which mating partners remain together during the annual cycle is a key question in avian behavioural ecology with implications for reproductive success through the continuation of productive partnerships and parental care. Life-time reproductive success is enhanced when productive pair bonds are maintained from year to year (Forslund and Larsson 1991; Black 2001; Sánchez-Macouzet et al.

*Correspondence: chris.redfern@newcastle.ac.uk

School of Natural \& Environmental Sciences, Newcastle University, NE2 $4 \mathrm{HH} \&$ Natural History Society of Northumbria, Great North

Museum:Hancock, Newcastle upon Tyne NE2 4PT, UK
2014; Wiley and Ridley 2018). Pair bonds facilitate biparental care (Cockburn 2006) which can increase offspring survival if extended after fledging (LópezIdiáquez et al. 2018). Thus, both parents of longlived species such as geese, swans and cranes remain together and migrate as a family with their offspring to non-breeding areas (Scott 1980; Black 2001; Alonso et al. 2004; Johnsgard and Mangelsen 2015). Such a strategy, however, is not a function of longevity; seabirds are also long-lived and provide post-fledging care to their offspring, but there is variability in parental care between different seabird taxa (Bried and Jouventin 2001). In terns (Sternidae), post-fledging care may be provided by both parents (Preddey 2008; Watson original author(s) and the source, provide a link to the Creative Commons licence, and indicate if changes were made. The images or other third party material in this article are included in the article's Creative Commons licence, unless indicated otherwise in a credit line to the material. If material is not included in the article's Creative Commons licence and your intended use is not permitted by statutory regulation or exceeds the permitted use, you will need to obtain permission directly from the copyright holder. To view a copy of this licence, visit http://creativecommons.org/licenses/by/4.0/. The Creative Commons Public Domain Dedication waiver (http://creativeco mmons.org/publicdomain/zero/1.0/) applies to the data made available in this article, unless otherwise stated in a credit line to the data. 
et al. 2012), and in some species over several months (Ashmole and Tovar 1968; Feare 1975; Barlow 1998) including post-breeding migration (Ashmole and Tovar 1968). Conversely, in Common Terns (Sterna hirundo), males may be more likely to provide parental care (Nisbet et al. 2011). Arctic Terns (S. paradisaea) provide some post-fledging parental care, but adults and young leave breeding areas soon after fledging (Withers 1973) and the extent of post-fledging care and whether partners remain together during migration and in the nonbreeding areas are unknown.

Nevertheless, pair bonds in terns and other seabirds can be stable between breeding seasons (Busse 1983; Cabot and Nisbet 2013) and raises the question whether breeding partners associate throughout the non-breeding season, which could be a factor in enhancing subsequent breeding success. Although mate familiarity is an important driver of reproductive success in Procellariiformes (Sánchez-Macouzet et al. 2014), Scopoli's Shearwater (Calonectris diomedea) pairs do not migrate or spend the non-breeding season together (Müller et al. 2015). Studies on paired Rhinoceros Auklets (Cerorhinca monocerata), Atlantic Puffins (Fratercula arctica) and Southern Rockhopper Penguins (Eudyptes chrysocome) also show a similar lack of association outside the breeding season (Thiebot et al. 2015; Fayet et al. 2017; Kubo et al. 2018). For terns, there are few studies on the extent of mating pair association on migration and in wintering areas. Male and female Common Terns from west Atlantic colonies may leave at different times (Nisbet et al. 2011) and mating pairs have different diets in wintering areas (Nisbet et al. 2002); similarly, on the basis of geolocator data, three pairs from an east Atlantic colony had different wintering areas along the West African coast (Becker et al. 2016). Furthermore, members of a pair of Sabine's Gulls (Xema sabini) wintered in different oceans 10,000 km apart (Davis et al. 2016).

The question whether or not breeding partners stay together for part or all of the post-breeding migration and wintering period has also been raised for Arctic Terns (Busse 1983) which migrate from high northernlatitude breeding colonies to non-breeding areas in the Antarctic and have one of the longest migrations of any species (Egevang et al. 2010; Fijn et al. 2013; Redfern and Bevan 2020a). The geographic scale of this migration provides an opportunity for an unambiguous test of partner association for a colonial seabird throughout the annual cycle. Given the mounting evidence for many migratory seabirds of minimal association outside the breeding season, it is likely that Arctic Tern pairs only re-associate after returning to the breeding colony. To test this hypothesis, leg-mounted global location sensors (GLS) or geolocators, which are well tolerated by Arctic Terns with high return rates (Redfern and Bevan 2020b), were fitted to pairs breeding in a European colony.

\section{Methods \\ Study site and geolocator attachment methods}

Intigeo-W65A9-SEA geolocators (Migrate Technology, Cambridge, UK) on plastic leg rings were fitted to 25 Arctic Terns nesting in the Inner Farne Courtyard, Farne Islands, Northumberland, UK (coordinates in decimal degrees: longitude $1.656^{\circ}$; latitude $55.617^{\circ}$ ) on 26 May-9 June 2017 (see Additional file 1: Fig. S1a) as part of a study on migration ecology. The age of 12 birds, previously ringed as chicks, was known accurately (range 8-17 years), two birds were ringed for the first time and the rest had been ringed previously as adults; Arctic Terns can breed from two years of age (see Additional file 1: Fig. S1b) and, therefore, for this latter group minimum ages ranged from 2 to 16 years. The Arctic Terns tagged with geolocators were from 18 nests: 7 where both pair members were tagged and 11 where one member was tagged. This analysis focussed on the birds tagged as pairs; in 3 pairs, birds were sexed on the basis of mating display, copulation behaviour or egg laying (Redfern et al. 2019). Birds in the other 4 pairs were sexed provisionally by within pair differences in total head length (Fletcher and Hamer 2003). Biometric sexing of Arctic Terns is reported to be $84 \%$ correct (Fletcher and Hamer 2003) so there is potential for error which should be borne in mind; molecular sexing was not possible because of funding constraints. The attachment method was as described previously (Redfern and Bevan 2020a, b) and the devices, weighing $<1 \mathrm{~g}$ fully mounted, represented $0.92 \% \pm 0.05$ (SD) of bird body mass. The following year, 24 returned and were recaptured, most in the period 25-27 May but 3 in 3-14 July. On capture and recapture, biometric data (body mass, total head length, wing length), clutch size and nest location (see Additional file 1: Fig. S1a) were recorded. The outcome (productivity) of nests was monitored weekly during routine work by National Trust rangers and ringing visits to the study site (see Additional file 1: Additional methods). Productivity, clutch-size data and other measures to assess geolocator effects are described in Additional file 1: Additional methods. The study was carried out under a ringing permit issued by the Ringing Scheme of the British Trust for Ornithology (BTO) with appropriate "Special Methods" endorsement permitting the use of leg-ring mounted geolocators.

\section{Data analysis}

Data were analysed using R 3.6.1 (R Core Team 2019). Estimates of latitude and longitude at dawn/dusk thresholds were derived from light-level data using FLightR (Rakhimberdiev et al. 2015, 2017) as described previously 
(Redfern and Bevan 2020a, b). A location accuracy of $50 \mathrm{~km}$ was assumed (Rakhimberdiev et al. 2016) as a rule of thumb. Stationary periods of two or more days were estimated by FLightR as periods with movements between twilight intervals of $<45 \mathrm{~km}$ (Rakhimberdiev et al. 2015). The shortest bird-to-bird location distances at each dawn/dusk threshold were calculated on a WGS84 ellipsoid using the distGeo function of package geosphere (Hijmans et al. 2019). For outward migration, distances were calculated from the date of departure from the last North Sea stationary period (Redfern and Bevan 2020b) of the last-departing bird of each pair to the day before the date of arrival of the first bird of that pair in 24-h Antarctic daylight. Before reaching the Antarctic Circle, birds enter the Antarctic sea-ice zone, characterised by a reduction in minimum temperatures recorded by geolocators to below $0{ }^{\circ} \mathrm{C}$; the dates of departure from this zone were used to indicate the start of return migration (Redfern and Bevan 2020a). Dates of arrival of each bird were the median dates of arrival to the Inner Farne coordinates, representing the last FLightR stationary period before geolocator retrieval. Bird-to-bird distances for return (inward) migration were calculated using similar criteria to outward migration. This inward phase also included the period in the Antarctic before return migration when seasonal progression allowed locations to be estimated by FlightR (Redfern and Bevan 2020a). Longitudes during 24-h daylight were as reported previously (Redfern and Bevan 2020a) and differences between partners in longitudinal separation were normally distributed (Shapiro test, $P=0.7$ ).

\section{Results}

\section{Pair status between seasons}

There were no indications from productivity estimates, clutch sizes or body mass for a negative effect on breeding performance of geolocator-tagged pairs (see
Additional file 1: Table S3, Fig. S2). The only bird that did not return in 2018, G79, was one of a tagged pair and was at least 10 years old in 2017; its female partner, G80, paired in 2018 with an untagged but colour-ringed male in a different part of the colony (see Additional file 1: Fig. S1a).

For the six other geolocator pairs from 2017, four remained the same in 2018 (Table 1) and nested in similar locations within the colony as in 2017 (see Additional file 1: Table S1; Fig. S1a). Two pairs from 2017 divorced. Female G84 (age $>4$ ) paired in 2018 with another geotagged bird (male G61, age $>9$ ) that had been paired with an untagged bird in 2017 (see Additional file 1: Table S2). G84 and its 2017 partner (male G30, age 15) remained within the same area of the colony but G30 had a new partner of unknown status. With respect to the remaining pair from 2017, female G33 (age 8) nested outside the courtyard in 2018, mated to an unringed bird (later trapped on the nest), whereas its 2017 partner (male G31, a new bird in 2017) nested in a similar area to its capture site in 2017 (see Additional file 1: Fig. S1a) but mated to a slightly younger female (age 7). An additional pair formed in 2018 between two geolocator-tagged birds from 2017 that were not paired together in the year of tagging (G66, age 8, with G69, age > 2).

\section{Migration phenology and routes of pairs in 2017}

Geolocator-tagged Arctic Terns from Inner Farne migrate south from the Irish Sea after moving west or south-west across the UK from the North Sea (Redfern and Bevan $2020 \mathrm{~b})$. For the geolocator-tagged pairs in 2017, four of the six male birds departed later (by between 5 and 18 days, mean 8) from the North Sea than their mate (Table 1), but the difference in departure date between males and females in pairs did not reach statistical significance (onesample $t$-test, $n=6, P=0.07$ ). Only one of these pairs was

Table 1 Pairs in 2017 that returned in 2018: migration phenology and 2018 status

\begin{tabular}{|c|c|c|c|c|c|c|c|c|c|}
\hline \multicolumn{4}{|c|}{ Female } & \multicolumn{4}{|l|}{ Male } & \multirow{2}{*}{$\begin{array}{l}2018 \\
\text { status** }\end{array}$} & \multirow[t]{2}{*}{ Depart diff*** } \\
\hline Code & Age* $^{*}$ & 2017 depart & 2018 arrive & code & Age $^{*}$ & 2017 depart & 2018 arrive & & \\
\hline G27 & 11 & 9 Aug & 4 May & G62 & $>5$ & 7 Aug & 11 May & $\mathrm{p}$ & -2 \\
\hline G16 & 10 & $20 \mathrm{Jul}$ & 12 May & G70 & 17 & 4 Aug & 7 May & $\mathrm{p}$ & $15^{\mathrm{a}}$ \\
\hline G33 & 8 & 1 Aug & 7 May & G31 & $>1$ & $31 \mathrm{Jul}$ & 3 May & $d$ & -1 \\
\hline G26 & 17 & $17 \mathrm{Jul}$ & 4 May & G44 & 8 & 4 Aug & 3 May & $\mathrm{p}$ & 18 \\
\hline G65 & $>4$ & 3 Aug & 3 May & $\mathrm{G} 40$ & $>5$ & 8 Aug & 5 May & $\mathrm{p}$ & 5 \\
\hline G84 & $>4$ & $21 \mathrm{Jul}$ & 15 May & G30 & 15 & 3 Aug & 2 May & $d$ & 13 \\
\hline
\end{tabular}

* Age (years) at capture in 2017

${ }^{* *}$ p, paired; d, divorced

${ }^{* * *}$ Difference in days between date of departure of male and female ( $\left.m-f\right)$ in 2017

${ }^{\text {a }}$ Breeding failure in 2017 
(See figure on next page.)

Fig. 1 Trajectories for the outward (left column) and inward (right column) migrations of each pair plotted on a global orthographic projection. Outward tracks start from the date that the last member of the pair departed. Females, filled circles; males, filled triangles. Points are locations estimated by FLightR and coloured by date according to the colour scale and legend to the right of each pair of orthographic global projections to illustrate the temporal coordination (or lack thereof) of the location of pair members. The points do not include the periods in 24-h daylight and before the start of return migration which are shown as plots of longitude by date in Additional file 1: Fig. S3

unsuccessful in breeding in 2017 and the male of this pair also departed later than the female (Table 1).

Migration trajectories are shown in Fig. 1 and were compared by calculating apparent bird-to-bird distances within each pair from the geolocation coordinates at the daily dawn and dusk thresholds (Fig. 2). Although the trajectories of most birds followed similar routes along the West African and Namibian coasts (Fig. 1), the birds were well separated from their partners (Fig. 2a). After rounding the southern tip of South Africa, pair members had distinct trajectories across the Indian Ocean (Fig. 1). Overall, there were large intra-pair separation distances at most outward migration stages and no contiguous geolocations of $<50 \mathrm{~km}$ separation before reaching 24-h daylight in the Antarctic. For three of the pairs, arrival locations in the Antarctic (24-h daylight) were separated by $70-90^{\circ}$ longitude, a separation distance around the Antarctic circle of $3000-4000 \mathrm{~km}$. Even when Antarctic arrival locations were similar, temporal separation was clearly evident (Fig. 1).

In Antarctic 24-h daylight, partner separation was maintained (see Additional file 1: Fig. S3a) except for one pair (G84-G30) in which both partners remained in a similar range of longitudes. However, the mean partner difference in longitude for this pair was $6.2^{\circ}$, equivalent to $275 \mathrm{~km}$ at the Antarctic Circle (99\% confidence range $4.2^{\circ}$ to $8.2^{\circ}$, equivalent to ca. 180 to $360 \mathrm{~km}$ at the Antarctic Circle; $\mathrm{df}=72$ ). For two others (see Additional file 1: Fig. S3), there was some convergence as the Antarctic summer progressed, possibly as a result of restricted food abundance that year (Redfern and Bevan 2020a). Once diel night/ day conditions had returned, there was some convergence in longitude as birds moved west around the Antarctic in preparation for return northward migration (see Additional file 1: Fig. S3b).

After the 24-h daylight phase, three birds had periods of separation $<50 \mathrm{~km}$ (i.e. within assumed geolocation error) lasting for 1, 3, and 9 days (G26-G44, G16-G70, and G33G31, respectively); these all occurred between 14 February and 12 March, before the start of return migration. Departures from the ice zone, marking the start of return migration, either differed markedly in time between partners or occurred at times of large spatial separation (Fig. 2b). Overall, there was no significant difference in departure time between sexes $(t$-test, $P=0.35)$. Subsequent return trajectories were mainly via the Atlantic, less constrained to the western coast of Africa, and more variable in location between pair members compared to outward migration but more consistent with respect to the timing of movement (Fig. 1).

Times of arrival of pairs (as units) in the breeding colony area were clear from plots of intra-pair distances (Fig. 2b) and ranged from ca. 5 to 17 May; the difference in arrival time between partners ranged from 1 to 13 days (median 4.5; Table 1). There was no significant difference between the sexes in dates of arrival to the breeding colony within the 2017 pairs (mean sex difference in date, female minus male: 2.3 days, one-sample $t$-test, null hypothesis of no difference, $P=0.4)$. For the 2 pairs that divorced, arrival dates of the females were later than the male by 4 days (G33) and 13 days (G84; Table 1); particularly for G84, her previous partner may have selected a new partner by the time she arrived and her new mate, G61, had arrived in the area 8 days before (7 May). For the pairs that remained the same as in 2017, the arrival dates of partners differed by between 1 to 7 days with no apparent sex bias (Table 1).

\section{Discussion}

Arctic Terns can be added to the list of migratory seabirds with no apparent pair association outside the breeding areas: partners departed from the colony at different times, leading to spatial separation throughout migration. Differences in departure time could depend on the extent of parental care and how this is distributed between partners, perhaps with a male bias (Nisbet et al. 2011). Therefore, asymmetric parental care may be a factor driving the lack of pair association after breeding. Arrival locations in the Antarctic differed, often with a wide and unambiguous partner separation, and there was no substantial evidence for partner associations during the inward migration. Although the locational resolution of geolocators is relatively low, the data show clearly that Arctic Terns paired during the breeding season are unlikely to remain together outside the breeding season. Apparent intra-pair associations of short duration may be coincidental, particularly if areas of predictable food abundance channel migration to specific routes or staging areas.

\section{Pair status}

Monogamous pair bonds of Arctic Terns reportedly persist from year to year (Cramp 1985) but there are few detailed analyses. Within a Helgoland colony, divorce rate was low for established pairs of experienced birds but more 

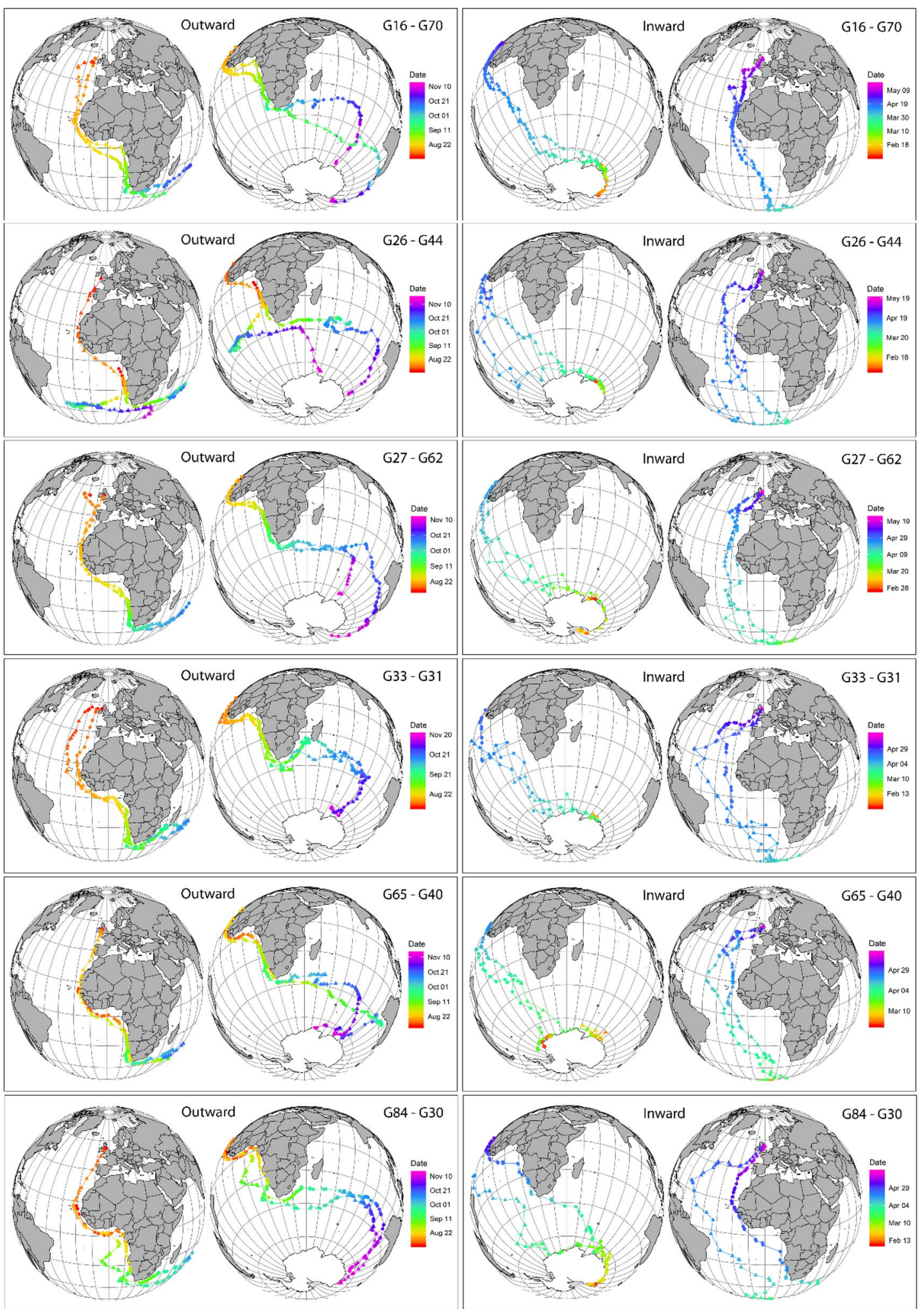

Fig. 1 (See legend on previous page.) 


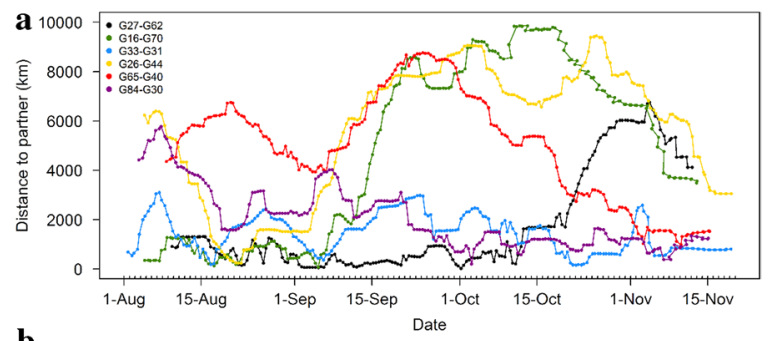

b

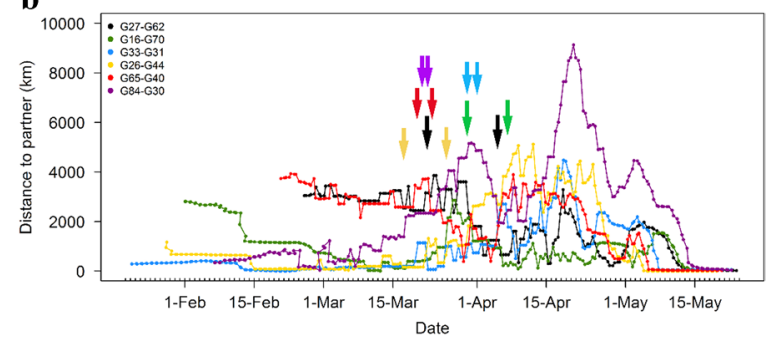

Fig. 2 Point-to-point distances between partners for outward a and inward $\mathbf{b}$ trajectories, based on locations (latitude, longitude) estimated using FLightR at the dawn and dusk thresholds each day. Line and point colour are distinct for each pair as indicated in the legend (top left) in the graphs. In $\mathbf{b}$, vertical arrows indicate the dates of departure from the Antarctic ice zone, marking the start of return migration (Redfern and Bevan 2020a) for the members of each pair, coloured according to the legend (top left). The reduction of point-to-point distances to $\mathbf{0}$ in $\mathbf{b}$ indicates the arrival of pairs (as units) back to the breeding colony

frequent in new pairs of young birds (Busse 1983). Arrival synchrony may be important in maintaining partner fidelity (Gunnarsson et al. 2004) and in Common Terns 20\% of pairs may divorce as a result of delays in partner arrival (González-Solís et al. 1999). For Arctic Terns, it has been suggested that partner loyalty, rather than loyalty to the breeding site (Bried et al. 2003), may be important in pair bond stability (Busse 1983).

In this sample of geolocator-tagged Arctic Terns, the divorce of one third of pairs suggests that divorce may be relatively frequent in this colony. Divorce may result from a range of factors (Johnston and Ryder 1987; Choudhury 1995). Youthful inexperience (sensu Busse 1983) is not a satisfactory explanation here, given that three of the divorcing birds were at least more than 4 years old. In the two pairs that divorced, females arrived after the males and the 13-day gap for one pair could have been a decisive factor. Nevertheless, arrival times derived from geolocation data are subject to geolocation accuracy and, ideally, visual observations of the arrival of individuals at the colony will be important for testing the contribution of arrival asynchrony to divorce. For the other divorced pair, the male was in the same nesting area as the previous year and his new mate was slightly younger than his previous partner-perhaps a better option for successful breeding (Flodin and Blomqvist 2012) particularly given the delay in arrival of his previous partner. In addition, as these birds were nesting in a dense part of the colony, competition for nest sites with extensive social mixing may also facilitate divorce by coercion (Jeschke et al. 2007).

The possibility that geolocators could have had an effect on pair-bonding interactions is an important caveat. In previous studies of Common and Roseate Terns (Sterna dougallii), geolocators produced adverse effects including reductions in body mass, breeding and survival (Nisbet et al. 2011; Mostello et al. 2014) which may increase divorce frequency. However, there was no evidence for an effect of geolocators in this study (and see Redfern and Bevan 2020b) or in a recent study using the same type of geolocator and attachment methods on Roseate Terns (Redfern et al. 2021). Given that the breeding success of geolocator-tagged pairs in this study was not detectably different from untagged pairs, an effect of geolocators in increasing divorce frequency in this study seems unlikely.

\section{Partial pair bonds}

Migration in family groups may increase fitness through parental care, but this may depend on the availability of predictable foraging resources and migration strategy, enabling the family to remain together at migration stopovers and wintering areas, as may be the case for geese, swans and cranes (Covas and Griesser 2007). When prey availability varies, birds may adapt foraging strategies depending on the benefits of foraging in groups or as individuals (Pöysä 1992; Sutton et al. 2015); prey availability could, therefore, place limits on the feasibility of continuing parental care away from breeding areas. Furthermore, staying together as a pair or family group when prey are scarce and widely distributed may not be an efficient strategy for individuals to maximise foraging success on migration and in non-breeding areas. Flying in close proximity can be energetically costly (Sankey and Portugal 2019), and staying with a particular individual, as opposed to a loose association of birds, requires the processing of sensory information, interaction rules and coordination of responses (Herbert-Read 2016) that may come at energetic cost. For long-distance migrants such as terns using a "fly-and-forage" strategy (Strandberg and Alerstam 2007; Hedenström and Åkesson 2016; Redfern et al. 2021), where opportunities for foraging on surface prey are unpredictable in the three-dimensional marine environment, there may be few advantages to remaining in pairs or a family group away from the breeding colony. Therefore, partial pair bonding, relatively stable from year to year but limited to the breeding colony, is likely to be a favourable evolutionary stable strategy for Arctic Terns and other migratory seabird species dependent on a patchy surface availability of forage fish varying at 
different oceanographic scales (Carroll et al. 2017; Holland et al. 2020).

The corollary of this argument is that for long-lived species where breeding and wintering areas are linked by fly-and-forage migration there may be a premium on breeding-site fidelity, with coordination of arrival times to maximise the chance of retaining a familiar partner for a short breeding season. In this context, divorce should be adaptive; as in Emperor (Aptenodytes forsteri) and King Penguins (A. patagonicus) which have a narrow time window for breeding (Bried et al. 1999), divorce may be the best strategy in a short breeding season when a familiar mate does not arrive soon enough and other suitable partners are available. For Arctic Terns, predictable foraging resources in the Antarctic could be a factor in ensuring synchrony of arrival back to the breeding colony. If foraging success is reduced by changes in Antarctic ice conditions (Redfern and Bevan 2020a), consequential delay and increased variability in dates of departure for return migration might have consequences for increasing divorce frequency.

\section{Conclusions}

After breeding, Arctic Tern partners departed from the colony at different times and were spatially well separated throughout their migration to the Antarctic, with distinct trajectories across the Indian Ocean. Partners remained separated in the Antarctic. Departures on return migration were also spatially and/or temporally separated, and partners remained separated until arrival back at the breeding colony. The maintenance of partial pair bonds where pairs only reunite at the breeding colony is likely to be the predominant pair-bond strategy for seabirds dependent on unpredictable foraging opportunities.

\section{Supplementary Information}

The online version contains supplementary material available at https://doi. org/10.1186/s40657-021-00268-3.

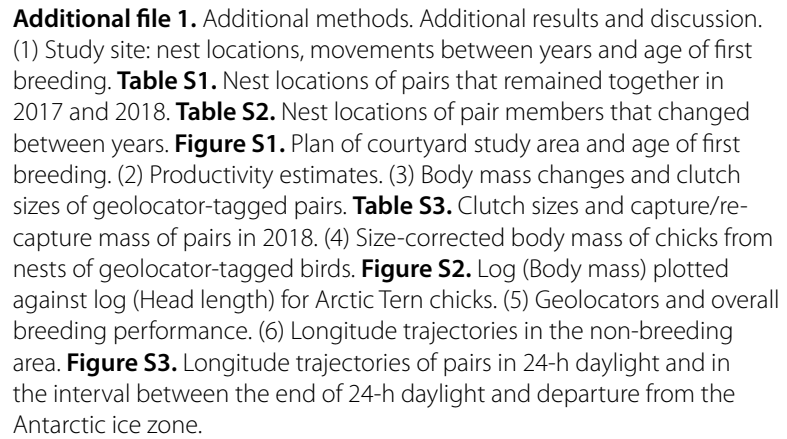

Additional file 1. Additional methods. Additional results and discussion (1) Study site: nest locations, movements between years and age of first breeding. Table S1. Nest locations of pairs that remained together in 2017 and 2018. Table S2. Nest locations of pair members that changed between years. Figure S1. Plan of courtyard study area and age of first breeding. (2) Productivity estimates. (3) Body mass changes and clutch sizes of geolocator-tagged pairs. Table S3. Clutch sizes and capture/recapture mass of pairs in 2018. (4) Size-corrected body mass of chicks from nests of geolocator-tagged birds. Figure S2. Log (Body mass) plotted against log (Head length) for Arctic Tern chicks. (5) Geolocators and overall breeding performance. (6) Longitude trajectories in the non-breeding area. Figure S3. Longitude trajectories of pairs in 24-h daylight and in the interval between the end of 24-h daylight and departure from the Antarctic ice zone.

\section{Acknowledgements}

I thank members of the Natural History Society of Northumbria who, together with a grant from the Seabird Group, funded geolocator purchase for this study. I also thank David Steel, the National Trust, and the Farne Islands Ranger Team on Inner Farne, led by Harriet Reid, for their support and encouragement. I am grateful to my colleague Richard Bevan for his support and contributions to the geolocator studies on the Farne Islands that we initiated in 2015, and I thank Diana Solovyeva and an anonymous reviewer for suggesting improvements to the manuscript.

\section{Authors' contributions}

The author read and approved the final manuscript.

\section{Funding}

This study was supported by the Natural History Society of Northumbria and the Seabird Group.

\section{Availability of data and materials}

The datasets supporting the conclusions of this article are available in the Seabird Tracking Database, in http://www.seabirdtracking.org/, datasets ID 1658 and 1659.

\section{Declarations}

\section{Ethics approval and consent to participate}

The study was carried out under a ringing permit issued by the Ringing Scheme of the British Trust for Ornithology (BTO) with appropriate "Special Methods" endorsement permitting the use of leg-mounted geolocators.

\section{Consent for publication}

Not applicable.

\section{Competing interests}

The author declares that he has no competing interests.

Received: 27 December 2020 Accepted: 8 June 2021

Published online: 18 June 2021

\section{References}

Alonso JC, Bautista LM, Alonso JA. Family-based territoriality vs flocking in wintering common cranes Grus grus. J Avian Biol. 2004;35:434-44.

Ashmole NP, Tovar SH. Prolonged parental care in royal terns and other birds. Auk. 1968:85:90-100.

Barlow M. Movements of Caspian Terns (Sterna caspia) from a colony near Invercargill, New Zealand, and some notes on their behaviour. Notornis. 1998;45:193-220

Becker PH, Schmaljohann H, Riechert J, Wagenknecht G, Zajková Z, GonzálezSolís J. Common Terns on the East Atlantic Flyway: temporal-spatial distribution during the non-breeding period. J Ornithol. 2016;157:927-40.

Black JM. Fitness consequences of long-term pair bonds in barnacle geese: monogamy in the extreme. Behav Ecol. 2001;12:640-5.

Bried J, Jouventin P. Site and mate choice in seabirds: an evolutionary approach. In: Schreiber EA, Burger J, editors. Biology of marine birds. CRC Marine Biology Series, 1. Boca Raton: CRC Press; 2001. p. 263-305.

Bried J, Jiguet F, Jouventin P. Why do Aptenodytes penguins have high divorce rates? Auk. 1999:116:504-12.

Bried J, Pontier D, Jouventin P. Mate fidelity in monogamous birds: a reexamination of the Procellariiformes. Anim Behav. 2003;65:235-46.

Busse K. Untersuchungen zum Ehe-, Familien- und Sozialleben der Küstenseeschwalbe (Sterna paradisaea PONT) mit besonderer Berücksichtigung des langzeitlichen Wandels der individuellen Beziehungen. Ökologie Der Vögel. 1983;5:73-110

Cabot D, Nisbet I. Terns. 1st ed. London: Collins; 2013.

Carroll G, Cox M, Harcourt R, Pitcher BJ, Slip D, Jonsen I. Hierarchical influences of prey distribution on patterns of prey capture by a marine predator. Funct Ecol. 2017;31:1750-60.

Choudhury S. Divorce in birds: a review of the hypotheses. Anim Behav. 1995;50:413-29.

Cockburn A. Prevalence of different modes of parental care in birds. Proc R Soc B Biol Sci. 2006;273:1375-83. 
Covas R, Griesser M. Life history and the evolution of family living in birds. Proc R Soc B Biol Sci. 2007;274:1349-57.

Cramp S. Handbook of the birds of Europe, the Middle East and North Africa. The Birds of Western Palearctic. Vol. IV. Terns to woodpeckers. Oxford: Oxford University Press; 1985.

Davis SE, Maftei M, Mallory ML. Migratory connectivity at high latitudes: Sabine's gulls (Xema sabini) from a colony in the Canadian high arctic migrate to different oceans. PLoS ONE. 2016;11:e0166043.

Egevang C, Stenhouse IJ, Phillips RA, Petersen A, Fox JW, Silk JRD. Tracking of Arctic terns Sterna paradisaea reveals longest animal migration. Proc Natl Acad Sci USA. 2010;107:2078-81.

Fayet AL, Shoji A, Freeman R, Perrins CM, Guilford T. Within-pair similarity in migration route and female winter foraging effort predict pair breeding performance in a monogamous seabird. Mar Ecol Prog Ser. 2017;569:243-52.

Feare CJ. Post-fledging parental care in Crested and Sooty Terns. Condor. 1975;77:368-70.

Fijn RC, Hiemstra D, Phillips RA, van der Winden J. Arctic Terns Sterna paradisaea from The Netherlands migrate record distances across three oceans to Wilkes Land, East Antarctica. Ardea. 2013;101:3-12.

Fletcher KL, Hamer KC. Sexing terns using biometrics: the advantage of withinpair comparisons: within-pair comparisons substantially improve the accuracy of sexing from biometrics for two congeneric species of seabird with monomorphic plumage and soft-tissue colouration. Bird Study. 2003;50:78-83.

Flodin LA, Blomqvist D. Divorce and breeding dispersal in the dunlin Calidris alpina: support for the better option hypothesis? Behaviour. 2012;149:67-80.

Forslund P, Larsson K. The effect of mate change and new partner's age on reproductive success in the barnacle goose, Branta leucopsis. Behav Ecol. 1991:2:116-22.

González-Solís J, Becker PH, Wendeln H. Divorce and asynchronous arrival in common terns, Sterna hirundo. Anim Behav. 1999;58:1123-9.

Gunnarsson TG, Gill JA, Sigurbjörnsson T, Sutherland WJ. Pair bonds: arrival synchrony in migratory birds. Nature. 2004;431:646.

Hedenström A, Åkesson S. Ecology of tern flight in relation to wind, topography and aerodynamic theory. Philos Trans R Soc B Biol Sci. 2016:371:20150396.

Herbert-Read JE. Understanding how animal groups achieve coordinated movement. J Exp Biol. 2016;219:2971-83.

Hijmans RJ, Williams E, Vennes C. geosphere: spherical trigonometry. R package geosphere version 1.5-10. 2019. http://CRAN.R-project.org/package= geosphere. Accessed 12 June 2021.

Holland MM, Smith JA, Everett JD, Vergés A, Suthers IM. Latitudinal patterns in trophic structure of temperate reef-associated fishes and predicted consequences of climate change. Fish Fish. 2020;21:1092-108.

Jeschke JM, Wanless S, Harris MP, Kokko H. How partnerships end in guillemots Uria aalge: chance events, adaptive change, or forced divorce? Behav Ecol. 2007;18:460-6.

Johnsgard PA, Mangelsen TD. A chorus of cranes: the cranes of North America and the world. 1st ed. Boulder: University Press of Colorado; 2015.

Johnston VH, Ryder JP. Divorce in larids: a review. Colon Waterbirds. 1987:10:16-26.

Kubo A, Takahashi A, Thiebot JB, Watanuki Y. Rhinoceros Auklet pair-mates migrate independently but synchronize their foraging activity during the pre-laying period. Ibis. 2018;160:832-45.

López-Idiáquez D, Vergara P, Fargallo JA, Martínez-Padilla J. Providing longer post-fledging periods increases offspring survival at the expense of future fecundity. PLoS ONE. 2018;13:e0203152.

Mostello CS, Nisbet ICT, Oswald SA, Fox JW. Non-breeding season movements of six North American Roseate Terns Sterna dougallii tracked with geolocators. Seabird. 2014:27:1-21.
Müller MS, Massa B, Phillips RA, Dell'Omo G. Seabirds mated for life migrate separately to the same places: behavioural coordination or shared proximate causes? Anim Behav. 2015;102:267-76.

Nisbet ICT, Montoya JP, Burger J, Hatch JJ. Use of stable isotopes to investigate individual differences in diets and mercury exposures among common terns Sterna hirundo in breeding and wintering grounds. Mar Ecol Prog Ser. 2002;242:267-74.

Nisbet ICT, Szczys P, Mostello CS, Fox JW. Female Common Terns Sterna hirundo start autumn migration earlier than males. Seabird. 2011;24:103-7.

Pöysä H. Group foraging in patchy environments: the importance of coarselevel local enhancement. Ornis Scand. 1992;23:159-66.

Preddey JM. Post-fledging parental care of a juvenile New Zealand fairy tern (Sterna nereis davisae). Notornis. 2008:55:159-61.

$R$ Core Team. R: a language and environment for statistical computing. Vienna: R Found. Stat. Comput; 2019. http://www.R-project.org/. Accessed 7 Oct 2019.

Rakhimberdiev E, Winkler DW, Bridge E, Seavy NE, Sheldon D, Piersma T, et al. A hidden Markov model for reconstructing animal paths from solar geolocation loggers using templates for light intensity. Mov Ecol. 2015;3:25.

Rakhimberdiev E, Senner NR, Verhoeven MA, Winkler DW, Bouten W, Piersma T. Comparing inferences of solar geolocation data against high-precision GPS data: annual movements of a double-tagged black-tailed godwit. J Avian Biol. 2016;47:589-96.

Rakhimberdiev E, Saveliev A, Piersma T, Karagicheva J. FLightR: an R package for reconstructing animal paths from solar geolocation loggers. Methods Ecol Evol. 2017;8:1482-7.

Redfern CPF, Bevan RM. Use of sea ice by arctic terns Sterna paradisaea in Antarctica and impacts of climate change. J Avian Biol. 2020a;51:e02318.

Redfern CPF, Bevan RM. Overland movement and migration phenology in relation to breeding of Arctic Terns Sterna paradisaea. Ibis. 2020b;162:373-80.

Redfern C, Kinchin-Smith D, Morrison P. Little-endian Arctic Tern and Roseate Tern in Northumberland. Br Birds. 2019;112:357-9.

Redfern CPF, Kinchin-Smith D, Newton S, Morrison P, Bolton M, Piec D. Upwelling systems in the migration ecology of Roseate Terns (Sterna dougallii) breeding in northwest Europe. Ibis. 2021;163:549-65.

Sánchez-Macouzet O, Rodríguez C, Drummond H. Better stay together: pair bond duration increases individual fitness independent of age-related variation. Proc R Soc B Biol Sci. 2014;281:20132843.

Sankey DWE, Portugal SJ. When flocking is costly: reduced cluster-flock density over long-duration flight in pigeons. Sci Nat. 2019:106:47.

Scott DK. Functional aspects of prolonged parental care in Bewick's swans. Anim Behav. 1980:28:938-52.

Strandberg R, Alerstam T. The strategy of fly-and-forage migration, illustrated for the osprey (Pandion haliaetus). Behav Ecol Sociobiol. 2007;61:1865-75.

Sutton GJ, Hoskins AJ, Arnould JPY. Benefits of group foraging depend on prey type in a small marine predator, the little penguin. PLOS ONE. 2015;10:e0144297.

Thiebot JB, Bost CA, Dehnhard N, Demongin L, Eens M, Lepoint G, et al. Mates but not sexes differ in migratory niche in a monogamous penguin species. Biol Lett. 2015;11:20150429.

Watson MJ, Spendelow JA, Hatch JJ. Post-fledging brood and care division in the roseate tern (Sterna dougallii). J Ethol. 2012;30:29-34.

Wiley EM, Ridley AR. The benefits of pair bond tenure in the cooperatively breeding pied babbler (Turdoides bicolor). Ecol Evol. 2018;8:7178-85.

Withers GD. A study of the population and behaviour of the Arctic Tern. 1973. https://www.repository.cam.ac.uk/handle/1810/284314. Accessed 12 June 2021. 